\title{
Necrotizing fasciitis of the chest wall: A clinical case report and literature review
}

\author{
CORNEL ADRIAN PETREANU ${ }^{1,2^{*}}$, TRAIAN CONSTANTIN ${ }^{3,4 *}$, RAZVAN IOSIFESCU $^{5,6}$, \\ ALEXANDRU GIBU $^{1}$, ALEXANDRU ZARIOSU ${ }^{1}$ and ALINA CROITORU ${ }^{7,8^{*}}$ \\ ${ }^{1}$ Department of Thoracic Surgery, 'Marius Nasta' National Institute of Pneumology, 050152 Bucharest; \\ ${ }^{2}$ Department of Thoracic Surgery, 'Carol Davila' University of Medicine and Pharmacy, 050474 Bucharest; \\ ${ }^{3}$ Department of Urology, 'Prof. Dr. Th. Burghele' Clinical Hospital, 061344 Bucharest; ${ }^{4}$ Department of Urology, \\ 'Carol Davila' University of Medicine and Pharmacy, 050474 Bucharest; ${ }^{5}$ Department of General Surgery, \\ 'Sf. Ioan' Clinical Emergency Hospital, 042122 Bucharest; ${ }^{6}$ Department of General Surgery, \\ 'Carol Davila' University of Medicine and Pharmacy, 050474 Bucharest; ${ }^{7}$ Department of Pneumology, \\ 'Marius Nasta' National Institute of Pneumology, 050152 Bucharest; ${ }^{8}$ Department of Pneumology, \\ 'Carol Davila' University of Medicine and Pharmacy, 050474 Bucharest, Romania
}

Received September 10, 2021; Accepted October 11, 2021

DOI: $10.3892 /$ etm.2021.11013

\begin{abstract}
Necrotizing fasciitis of the chest wall is a very rare pathology, but with significant mortality, representing a therapeutic challenge. All international reports indicate the need for early diagnosis and an aggressive medical-surgical attitude in order to improve the prognosis. In addition to a review of literature, we present a case developed secondary to a thoracic pleural drainage for pyopneumothorax associated with significant bronchopleural fistula in a destroyed tuberculous left lung. Along with medical treatment, extensive surgical debridement was required. Despite drainage incisions and negative pressure wound therapy (NPWT), the evolution of the fasciitis was difficult, due to bronchopleurocutaneous fistula. Thus, the Azorin procedure (transcervical mediastinoscopic closure of the left main bronchus) was performed. Once this procedure was completed, the inflammatory phenomena were controlled which allowed for a second step consisting of left pneumonectomy, with the application of specific methods for the prevention of bronchial fistula. The clinical case was a
\end{abstract}

Correspondence to: Dr Cornel Adrian Petreanu, Department of Thoracic Surgery, 'Marius Nasta' National Institute of Pneumology, 90 Șoseaua Viilor, 050152 Bucharest, Romania

E-mail: petreanu.cornel@yahoo.com

*Contributed equally

Abbreviations: NPWT, negative pressure wound therapy; MOF, multiple organ failure; Fr, French size, BAAR, acid-alcohol resistant bacillus

Key words: necrotizing fasciitis, chest wall infection, bronchopleural fistula, transcervical mediastinoscopic bronchial closure, tuberculous destroyed lung therapeutic challenge requiring a complex, staged, multidisciplinary approach due to both the immunocompromised terrain and the severity of the lesions. In conclusion, early recognition and aggressive and combined application of medical and surgical treatment methods can ensure therapeutic success.

\section{Introduction}

Necrotizing fasciitis of the chest wall is a rare pathology, but is a life-threatening condition with a high mortality rate. It has an aggressive character, rapidly extensive and mutilating by widespread musculocutaneous necrosis, with increased mortality because it is quickly associated with general septic phenomena with the establishment of multiple organ failure (MOF) (1-3).

In the 2000's, a total of 4 cases per million were reported in the USA and 10 cases per million were reported in Western Europe, while the incidence on the North American continent was approximately 1,000 cases per year. There is no predisposition in regards to sex and it has been observed more often in elderly patients and rarely in children. The first mention case was made by Hippocrates in the 5th century BC, as a complication of an erysipelas. In the 18th century, it was described by English doctors as 'gangrenous ulcer', 'rotten ulcer' or 'hospital gangrene' (4-6).

In 1983, Pingleton and Jeter reported extensive thoracic wall gangrene with Bacteroides melaninogenicus and Viridans streptococci after minimal pleurotomy for empyema. Vanecko reported clostridial myodestruction of the large pectoralis major and of the serratus anterior after minimal pleurotomy in a patient with Boerhaave's syndrome (7).

Thoracic necrotizing fasciitis has been reported as primary when there is no lesion of cutaneous or secondary when there is a discontinuity of skin integrity, neighborhood (cervical, abdominal) or proper thoracic.

In most cases, it has been shown to be directly related to the state of immunodeficiency, secondary to an unbalanced 
diabetes mellitus, steroid treatment, hematological or oncological disease (8-11). This proven link does not exclude the possibility of this pathology in an apparently immunocompetent patient.

The case presented is a secondary one to thoracic intervention (minimal pleurotomy for pyopneumothorax) in a patient with active pulmonary tuberculosis. Its peculiarity results from the presence of a bronchopleural fistula that favored and aggravated the proper fasciitis and that required a complex surgical approach, both for infection control and for curative purposes.

\section{Case report}

The case of a 43-year-old man, cachectic, with a history of left pulmonary tuberculosis treated 10 years ago, is presented. He presented to the emergency room of the National Institute of Pneumology, Bucharest, with acute symptoms such as severe dyspnea, cough with mucopurulent sputum with onset of about 10 days, amid physical and mental asthenia installed for several months. Biologically, the patient had severe anemia (hemoglobin level, $6.92 \mathrm{~g} / \mathrm{dl}$ ) and leukocytosis $(16,000 / \mu \mathrm{l})$. The $\mathrm{X}$-ray revealed a left pyopneumothorax and a minimum left pleurotomy was performed.

Subsequently, despite the $32 \mathrm{CH}$ tube drainage, major purulent air and fluid losses were found both at the level of the underwater sealed drainage and peristomal. These major periorificial losses were associated with massive local parietal contamination with rapid extension of the necrotic-suppurative phenomena, up to the abdominal level, respectively of the left flank (Fig. 1). Thus, at approximately 48 h, it was necessary to apply drainage incisions with debridement at the thoracic parietal level, in addition to the strong antibiotic treatment.

In addition to local betadine lavage and repeated debridement, negative pressure wound therapy (NPWT) was applied to areas at a relative distance from the pleurotomy orifice. NPWT could not be applied extensively due to the lack of tightness secondary to extensive parietal air loss. Pleural lavage has been shown to be dysfunctional due to bronchial aspiration. All of these elements were in favor of a clinically significant bronchopleural fistula that could not be objectified bronchoscopically.

The sputumexamination indicated the presence of BAAR++, establishing the specific treatment. Streptococcus pyogenes was identified in the wounds and pleural fluid and appropriate antibiotic treatment was instituted.

Chest computed tomography (CT) examination indicated the presence of a destroyed tuberculous left lung, with pyopneumothorax, with parietal defects of skin, subcutaneous and even muscle tissue (Fig. 2).

Considering the evolution of the patient towards the degradation of the general condition, of extension of the parietal phenomena, the Azorin procedure of transcervical mediastinoscopic closure and section of the left primitive bronchus was chosen, in the hope of diminishing the periorificial air losses and of the implicit parietal contamination (Fig. 3A).

After $48 \mathrm{~h}$, the patient showed improvement with diminishing and stoppage of the evolution of acute necrotic suppurative phenomena at the parietal level. Intrapleural lavage was introduced and daily debridement and dressings with significant granulation were continued (Fig. 3B). Subfebrility was recorded for several days, relatively easily controlled with usual antipyretics. Antituberculosis and antibiotic treatments were carefully continued. The samples confirmed the presence of Pseudomonas aeruginosa and a nosocomial contamination with methicillin-resistant Staphylococcus, requiring the adaptation of antibiotic therapy.

At 21 days postoperatively, a left pneumonectomy was performed, with an abundant intraoperative lavage with betadine serum. The pneumonectomy technique was a simple one, identifying relatively easily the distal bronchial stump, mechanically closed by the previous procedure. The proximal bronchial stump was not exposed, in order to avoid fistulization. In addition, a flap of minimal pericardial fat was applied at this level. Moreover, excision of the pleurocutaneous fistulous tract with suture was performed and a Clagett-type drain-wash (drainage-circuit lavage with apical inlet and posterobasal recovery tube) with $1,000 \mathrm{ml}$ of betadine serum daily for 4 days postoperatively was placed. The evolution was favorable, the patient being closely monitored clinically and radiologically for one year.

\section{Discussion}

In the literature, the bacteria involved in the pathogenesis of necrotizing parietal fasciitis is termed 'flesh eating bacteria', although there is no proper mechanism of 'tissue devouring'. The mechanisms of the bacteria involved are multiple and include bacterial necrotoxins (Clostridium perfringens, Streptococcus pyogenes), thrombosis and microvascular coagulation with secondary necrosis by heparinase release, anaerobic environment, release of beta lactamases that interfere with antibiotic activity $(2,4,11)$.

There is a general specificity of germs depending on the type of fasciitis, but it is not absolute. Three classes of fasciitis are described based on the bacteriological criterion. The first class is a polymicrobial one, with combinations of gram-positive cocci, gram-negative bacilli and anaerobes of the Clostridium type. They are located especially in the chest and perineum. It especially affects the elderly and the immunocompromised. Often, no obvious trauma or cause is identified, but the presence of skin discontinuity from old abscesses, perforations or bacterial translocations is assumed. A special mention is made of the clostridial subtype that produces gangrene with specific gas, this being more and more rarely described with the improvement of sanitary conditions and hygiene. Its mortality exceeds $50 \%(11,12)$. From a practical point of view, the recommendation is that in the case of a rapid installation of local phenomena (of the order of hours) to take into account the presence of Clostridium and Streptococcus species.

Type II involves fasciitis with group A beta hemolytic Streptococcus alone or in combination with Staphylococcal species. In addition, it shows a rapid evolution with high toxicity, observing an impairment of younger and healthier patients than in type I. Type III is specifically described on the West coast of the USA with gram-negative marine Vibrio vulnificus type.

Starting from the criterion of mechanism and topography, Urschel et al (2) and Moustaide et al (10) reported primary forms of fasciitis with the involvement mainly 


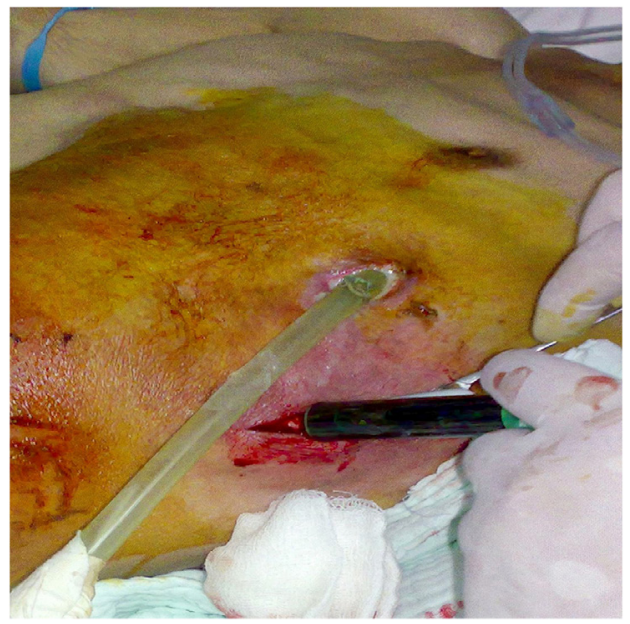

Figure 1. Finger test, incisions and debridement washing with betadine serum.
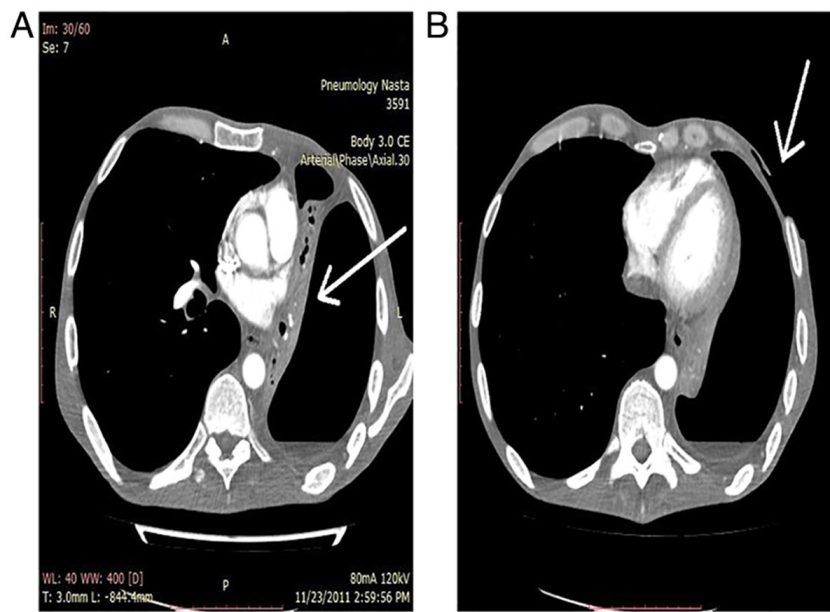

Figure 2. Chest computed tomography. (A) Lung destruction. (B) Areas of parietal destruction.

of Streptococcus pyogenes, but also Vibrio vulnificus, Clostridium perfringens or Bacteroides fragilis, most cases being polymicrobial.

The secondary ones involve a specific flora and a specific behavior. The more frequent deep cervical infectious processes are associated with mediastinitis due to the cervical fascial anatomy and their connections to the mediastinal fasciae (11). The superficial ones also expand gravitationally, but superficially developing fasciitis of the chest wall, with the aggravation of the initial prognosis $(11,13-20)$. The most common causes include dental abscesses, but have also been cited as secondary to Bezold abscesses or to puncture site for central catheterization. In terms of flora, Klebsiella pneumoniae has been identified as the most common and most aggressive pathogen, associated with increased mortality (approximately 60\%) (15). Klebsiella pneumoniae has also been identified in nosocomial forms, associated with multidrug resistance and implicitly with high mortality (15).

Abdominal extension has been reported following a retroperitoneal abscess associated with emphysematous pyelonephritis. This pathology is reported secondary to high urinary tract infections with Escherichia coli,
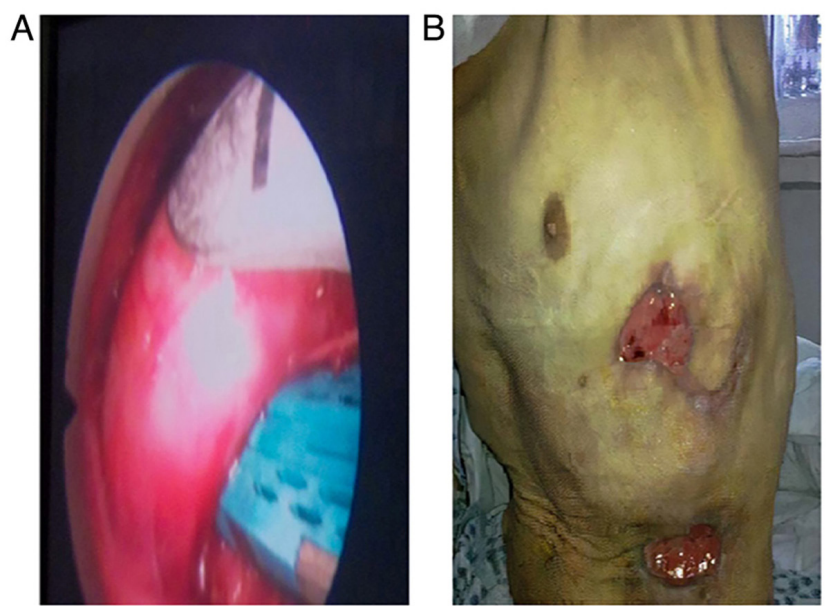

Figure 3. (A) Azorin procedure, intraoperative image (left primitive bronchus, inside the endoscopic stapler). (B) Granulation of skin lesions after bronchial closure, 3 weeks after.

K. pneumoniae, Enterobacter aerogenes, Proteus mirabilis, Pseudomonas species, with anaerobes, Streptococci and Candida (21,22). Rebai et al (23) presented a case of perforating appendicitis resulting in secondary necrotizing fasciitis of the anterior abdominal and thoracic wall,identifying gram-negative opportunistic pathogens (Escherichia coli, Pseudomonas aeroginosus, Acinetobacter).

Secondary necrotizing thoracic parietal fasciitis is most often reported due to pleurotomies or surgery for empyema, as in the present case. In fact, they are described secondary to any thoracic intervention, but more often secondary to extensive or esophageal resection, but also secondary to thoracocentesis or thoracic drainage in Boerhaave syndrome (1-3,24,25).

Thus, globally from a bacteriological point of view, anaerobes have been identified which include: Bacteroid species, very often; Peptostreptococcus species, Clostridium perfringens, Fusobacterium lentum, Microaerophilic streptococci, Eubacterium, but also the aerobes, Streptococcus pyogenes, Enteroccus, and species of Streptococcus. Most associated other anaerobic and aerobic flora, rarely being unimicrobial. Thus, in $76 \%$ of cases a polymicrobial flora was identified (2,25-27).

In the present case, Streptococcus pyogenes with general antibiotic sensitivity was initially identified in the wounds. Subsequently, repeated sampling identified the presence of Aeruginosa pseudomonas and methicillin-resistant Staphylococcus, revealing nosocomial contamination and requiring specific treatment.

Sometimes, bacteriological samples obtained during surgical debridement prove sterile, but only because of the introduction of aggressive antibiotic treatments initiated in other clinics (16). Nosocomial superinfection adds a negative prognostic factor, being quite common due to the large areas needed to be managed and the long period of treatment.

The processes of fasciitis with induration, collection, erythema, pain, crackles have been obviously identified, usually at 3-4 days and only where aggressive and early intervention could be mastered (2). A characteristic frequently present in this pathology is represented by the discrepancy between the apparently minimal visible skin damage and the noisy systemic symptoms (28). 
For any suspicion of necrotizing fasciitis, the finger test is recommended. Thus, after local anesthesia, an incision $2-3 \mathrm{~cm}$ wide enough to insert the index finger to the deep fascia is made. The lack of bleeding or the appearance of a gray necrosis fluid are very suggestive for necrotizing fasciitis. The easy digital dissection of the planes with the minimum tissue resistance is a golden standard for diagnosis (Fig. 1) (4,29-31).

In the case of obvious clinical forms, imaging confirmation is required to assess the extent. The presence of air bubbles is easily made based on the standard radiological examination and, more recently, POCUS (point of care ultrasound). The routine paraclinical imaging examination for diagnosis and for the evaluation of extension is the CT examination (Fig. 2) (22,27,32). Thus, a CT examination can show specific signs of parietal thoracic necrotizing fasciitis: signs of parietal collections, edema in the subcutaneous and fatty tissue, gas collections locally or with locoregional extension. POCUS examination is becoming more widespread due to its ease of use even when we have minimal suspicion. Local pain may limit the examination, but by intensity disproportionate to the pressure may suggest the diagnosis $(22,29,32,33)$.

Surgical treatment is based on debridement through wide drainage incisions. The use of peroxidase, hyperbaric oxygen therapy, antibody therapy has been reported $(2,4,34,35)$. Debridement gestures will be applied repeatedly with daily dressing changes $(19,36,37)$.

Negative pressure wound therapy (NPWT) has greatly reduced the mortality even in extensive forms, doubled by measures of muscle plastics, split skin grafts or secondary closure. The essential condition is the early recognition of suppurative phenomena (36-40).

In the present case, it was not possible to practice extensive NPWT, due to air loss near the pleurotomy orifice. Wound cleansing was achieved by stopping active contamination, applying bronchial stump closure and by dressing and irrigating with betadine solution, sometimes repeated daily.

Major damage can cause chest wall stability problems when extensive costal resections are performed $(1,41)$, sometimes requiring even prolonged ventilatory support to facilitate pleural symphysis and the appearance of stabilizing thickening of pleura. Major damage and extensive lung damage may require the practice of open drainage (open window-Eloesser thoracomyoplasty) and Clagett-type lavage (19,36,37).

In the associated forms of mediastinal damage with parietal fasciitis, various techniques can be used in addition to superficial debridement incisions, such as mediastinoscopy and thoracoscopy for mediastinal debridement and drainage $(42,43)$.

The mortality rate was found to be $70 \%$, if delayed for more than $24 \mathrm{~h}$ after clinical diagnosis for drainage and less than $30 \%$ when intervened in less than $24 \mathrm{~h}$. The mortality rate is $71 \%$ if limited debridement is performed and $43 \%$ if extensive and repeated debridement is performed (12).

Rapid recognition, prompt and combined application of aggressive surgical gestures with large debridement and NPW therapy associated with specific antibiotic therapy were essential to reduce sepsis and multisystem organ failure phenomena.

The case presented here was a challenge both in terms of thoracic parietal inflammatory phenomena, and in terms of the aggravating mechanism of bronchopleural fistula. In addition, performing a left pneumonectomy in an infected environment, especially in an immunocompromised, cachectic patient involved an increased risk of fistulization, with increased morbidity and mortality.

In fact, the Azorin procedure was initially described for the treatment of postpneumonectomy bronchopleural fistulas on long bronchial stump, but can also be practiced as a preexeresis, preventive method of choice in patients at risk of postpneumonectomy fistulization (Fig. 3A, bronchial left main into stapler). The principle is to do bronchial sutures in a clean, uncontaminated environment at the mediastinal level.

The procedure was found to be the ideal solution for a destabilized patient with a severe infectious status, in whom the parietal necrotic suppurative phenomena could not be controlled. In addition, it allowed a faster recovery than a classic open window Eloesser thoracoplasty procedure.

In addition, for the preventive purpose of bronchopleural fistula secondary to pulmonary resection, a patch of pericardial fat was applied over the bronchial stump and a Clagett-type lavage was established for 4 days with $1,000 \mathrm{ml}$ of betadine solution daily.

In conclusion, necrotizing fasciitis is a pathology with significant mortality, which must always be taken into account when there is interruption of skin continuity, traumatic or surgical or when there are minimal elements of suspicion of damage to subcutaneous cellulite-type tissues. Early recognition and prompt application of complex medical-surgical treatment ensures good results. Antibiotic therapy after initiation will be adapted according to antibiograms, especially in aggressive forms of nosocomial infections. The application of incisions and wide debridement ensures the control and limitation of the destructive phenomena. The entire surgical arsenal will be applied to limit the spread of infection as fast as possible, in order to achieve a successful outcome.

\section{Acknowledgements}

Professional editing, linguistic and technical assistance was performed by Irina Radu, Individual Service Provider. The figures and case have been previously presented as a poster at an abstract meeting for the European Respiratory Journal 40: P2414, 2012. The European Respiratory Society Programme Team has granted the approval to submit a full article based on the abstract to any other journal.

\section{Funding}

No funding was received.

\section{Availability of data and materials}

Data available on request from the authors.

\section{Authors' contributions}

CAP wrote the manuscript in light of the literature data with support from AG and AZ. CAP and RI conceived of the presented idea. CAP and TC carried out the main intervention. AC treated and followed the patient. All authors read and approved the final manuscript. 


\section{Ethics approval and consent to participate}

This case report was approved by the Ethics Commission of the National Institute of Pneumology, Bucharest, Romania (no. 23515 from 13.10.2021).

\section{Patient consent for publication}

Written informed consent was obtained from the patient on 12.10.2021.

\section{Competing interest}

The authors declare they have no competing interests.

\section{References}

1. Safran DB and Sullivan WG: Necrotizing fasciitis of the chest wall. Ann Thorac Surg 72: 1362-1364, 2001.

2. Urschel JD, Takita $H$ and Antkowiak JG: Necrotizing soft tissue infections of the chest wall. Ann Thorac Surg 64: 276-279, 1997.

3. Pingleton SK and Jeter J: Necrotizing fasciitis as a complication of tube thoracostomy. Chest 83: 925-926, 1983.

4. Hakkarainen TW, Kopari NM, Pham TN and Evans HL: Necrotizing soft tissue infections: Review and current concepts in treatment, systems of care, and outcomes. Curr Probl Surg 51: 344-362, 2014

5. Loudon I: Necrotizing fasciitis, hospital gangrene, and phagedena. Lancet 344: 1416-1419, 1994.

6. Descamps V, Aitken J and Lee M: Hippocrates on necrotizing fasciitis. Lancet 344: 556, 1994.

7. LoCicero J III and Shields T: Infections of the chest wall. Chapter 45. In: Thoracic surgery. Shields TW, Locicero J III, Ponn RB and Rusch VW (eds). 6th edition. Lippincott Williams \& Wilkins, Philadelphia, PA, 2009.

8. Rabiou S, Lakranbi M, Issoufou I, Ammor FZ, Belliraj L, Ouadnouni Y and Smahi M: About two cases of primitive necrotizing fasciitis of the chest wall. Rev Mal Respir 33: 401-404, 2016 (In French)

9. Belliraj L, Sani R, Issoufou I, Lakranbi M, Ouadnouni Y and Smahi M: Primitive necrotizing fasciitis of the thoracic wall: Fatal complication of diabetic patient. Tunis Med 96: 520-523, 2018

10. Moustaide K, Nassiri A, Aqil N, Baybay H, Gallouj S and Mernissi FZ: Primary necrotizing fasciitis of the chest wall. J Stem Cell Res Ther 4: 95-96, 2018.

11. Abbasi Z, Inam H, Das S, Neel S and Fatimi SH: Fungal cervical abscess complicated by necrotizing fasciitis leading to descending necrotizing mediastinitis: A case report. Cureus 11: e5369, 2019.

12. Freischlag JA, Ajalat G and Busuttil RW: Treatment of necrotizing soft tissue infections. The need for a new approach. Am J Surg 149: 751-755, 1985.

13. Medeiros Júnior R, Melo Ada R, Oliveira HF, Cardoso SM and Lago CA: Cervical-thoracic facial necrotizing fasciitis of odontogenic origin. Braz J Otorhinolaryngol 77: 805, 2011 (In English, Portuguese).

14. Gore MR: Odontogenic necrotizing fasciitis: A systematic review of the literature. BMC Ear Nose Throat Disord 18: 14, 2018.

15. Rahim GR, Gupta N, Maheshwari P and Singh MP Monomicrobial Klebsiella pneumoniae necrotizing fasciitis: An emerging life-threatening entity. Clin Microbiol Infect 25 316-323, 2019

16. Bakshi J, Virk RS, Jain A and Verma M: Cervical necrotizing fasciitis: Our experience with 11 cases and our technique for surgical debridement. Ear Nose Throat J 89: 84-86, 2010.

17. Mao JC, Carron MA, Fountain KR, Stachler RJ, Yoo GH, Mathog RH and Coticchia JM: Craniocervical necrotizing fasciitis with and without thoracic extension: Management strategies and outcome. Am J Otolaryngol 30: 17-23, 2009.

18. Silva VA, Almeida AS, Lavinsky J, Pauna HF, Castilho AM, Chone CT and Crespo AN: Thorax necrotizing fasciitis following Bezold's abscess. Clin Case Rep 8: 2848-2851, 2020.

19. Lalwani AK and Kaplan MJ: Mediastinal and thoracic complications of necrotizing fasciitis of the head and neck. Head Neck 13 531-539, 1991.
20. Pirvu A, Angelescu D and Savu C: Localized fibrous tumor of the pleura an unusual cause of severe hypoglycaemia. Case report. Rev Med Chir Soc Med Nat Iasi 120: 628-630, 2016.

21. Khaladkar SM, Jain KM, Kuber R and Gandage S: Necrotizing fasciitis of thoracic and abdominal wall with emphysematous pyelonephritis and retroperitoneal abscess. J Clin Imaging Sci 8: 7, 2018.

22. Tsitouridis I, Michaelides M, Sidiropoulos D and Arvanity M: Renal emphysema in diabetic patients: CT evaluation. Diagn Interv Radiol 16: 221-226, 2010.

23. Rebai L, Daghmouri A and Boussaidi I: Necrotizing fasciitis of chest and right abdominal wall caused by acute perforated appendicitis: Case report. Int J Surg Case Rep 53: 32-34, 2018.

24. Floether L, Bucher M, Benndorf R and Burgdorff AM: Necrotizing fasciitis caused by the treatment of chronic non-specific back pain. BMC Anesthesiol 20: 245, 2020.

25. Cai Y, Cai Y, Shi W, Feng Q and Zhu L: Necrotizing fasciitis of the breast: A review of the literature. Surg Infect (Larchmt) 22: 363-373, 2021.

26. Andreasen TJ, Green SD and Childers BJ: Massive infectious soft-tissue injury: Diagnosis and management of necrotizing fasciitis and purpura fulminans. Plast Reconstr Surg 107: 1025-1035, 2001.

27. Rogers PJ, Lewis BM, Odak M and Bucher J: Spontaneous necrotizing fasciitis. Cureus 12: e11880, 2020.

28. Jansen-Winkeln B, Langer S, Hoang Do $M$ and Gockel I: Necrotizing fasciitis. Chirurg: Jan 9, 2020 (Epub ahead of print). doi: 10.1007/s00104-019-01108-3.

29. Goh T, Goh LG, Ang $\mathrm{CH}$ and Wong $\mathrm{CH}$ : Early diagnosis of necrotizing fasciitis. Br J Surg 101: e119-e125, 2014.

30. Hösl VM, Kehrer A and Prantl L: Necrotizing fasciitis-a surgical emergency. Unfallchirurg 123: 807-815, 2020 (In German).

31. Neeki MM, Dong F, Au C, Toy J, Khoshab N, Lee C, Kwong E, Yuen HW, Lee J, Ayvazian A, et al: Evaluating the laboratory risk indicator to differentiate cellulitis from necrotizing fasciitis in the emergency department. West J Emerg Med 18: 684-689, 2017.

32. Savu C, Melinte A, Balescu I and Bacalbasa N: Azygos vein anevrysm mimicking a mediastinal mass. In Vivo 34: 2135-2140, 2020.

33. Yamaoka M, Furusawa K, Uemsatsu T and Yasuda K: Early evaluation of necrotizing fasciitis with use of CT. J Craniomaxillofac Surg 22: 268-721, 1994.

34. Tata MD, Kwan KC, Abdul-Razak MR, Paramalingam S and Yeen WC: Adjunctive use of superoxidized solution in chest wall necrotizing soft tissue infection. Ann Thorac Surg 87: 1613-1614, 2009.

35. Riseman JA, Zamboni WA, Curtis A, Graham DR, Konrad HR and Ross DS: Hyperbaric oxygen therapy for necrotizing fasciitis reduces mortality and the need for debridements. Surgery 108: $847-850,1990$

36. Deschamps C, Allen MS, Miller DL, Nichols FC III and Pairolero PC: Management of postpneumonectomy empyema and bronchopleural fistula. Semin Thorac Cardiovasc Surg 13: 13-19, 2001

37. Perentes JY, Abdelnour-Berchtold E, Blatter J, Lovis A, Ris HB, Krueger T and Gonzalez M: Vacuum-assisted closure device for the management of infected postpneumonectomy chest cavities. J Thorac Cardiovasc Surg 149: 745-750, 2015.

38. O'Connor J, Kells A, Henry S and Scalea T: Vacuum-assisted closure for the treatment of complex chest wounds. Ann Thorac Surg 79: 1196-1200, 2005.

39. Birnbaum DJ, D'Journo XB, Casanova D and Thomas PA: Necrotizing fasciitis of the chest wall. Interact Cardiovasc Thorac Surg 10: 483-484, 2010.

40. Garcia-Orozco VH, Solar-Aguirre C and Lopez-Yerena I: Successful treatment of necrotizing fasciitis using handmade negative pressure system wound therapy. Cir Cir 88 (Suppl 1): S24-S27, 2020.

41. Kovács O, Szántó Z and Krasznai G: Fulminant isolated necrotizing fasciitis of the chest wall, complicating thoracic empyema. Magy Seb 69: 27-30, 2016 (In Hungarian).

42. Zhu ZC, Yang X, Zheng F, Zheng L and Xu TS: Clinical study of cervical necrotizing fasciitis accompanied with descending necrotizing mediastinitis treated with cervical double parallel incision combined with mediastinoscope or thoracoscope. Zhonghua Kou Qiang Yi Xue Za Zhi 54: 309-314, 2019 (In Chinese).

43. Peetermans M, de Prost N, Eckmann C, Norrby-Teglund A, Skrede S and De Waele JJ: Necrotizing skin and soft-tissue infections in the intensive care unit. Clin Microbiol Infect 26: 817, 2020. 